\title{
The Effect of Signs Design of Wayfinding to Elders in Hospital: Take National Taiwan University College of Medicine for Example*
}

\author{
FEI Man-chang \\ Ming-Chuan University, Taoyuan, Taiwan
}

\begin{abstract}
Taiwan had officially entered aging society in 1993, and meantime the birthrate reaches its lowest point again and again. The constitution of population dramatically turns into an elder and low-birthrate society. Therefore, the ratio of elders living along is increasing yearly. When the elders need to deal the illness and go to hospital along, decays come from degeneration might have affect on their activity in accessible environment in hospital. Signs is a vital tool for delivering and communicating information in the road sign system. Whether the elders can identify the signs in hospital clearly becomes an important issue in the current research. To understand the affect of signs design in hospital to elders, the research reviewed and gained insight of degeneration in both physical and psychological of elders and the proper principal of signs design for elders. The research surveys in Taipei City, which has densest medical center, and mainly focus on National Taiwan University College of Medicine, which has hundred years of history (founded in 1895). The research conducts field survey in both old and new buildings of National Taiwan University College of Medicine in August, 2015. The survey includes five types of signs design: Public Facilities, Prohibition, Safety, Warning, and Commercial Facilities. The result from article review indicates the most salient psychological degenerations includes the change in cognitive function, decay of memory, and deceleration of information processing; physical degenerations includes the decay of vision. As a result, the following properties should be taken into consideration when designing sings for elders: (1) The proper ratio of graphic and text. (2) Avoid using colors or matches difficult to identify by elders, like purple, blue, and green. (3) Take the visibility, legibility, identity, attention, and memory into consideration, there should be $70 \%$ differentiation in contrast between text of sign and background. (4) Avoid using multi-meaning graphic, keep the design simple. The result from the survey of National Taiwan University College of Medicine indicates: (1) Using mainly on graphic and text as subsidiary, part of the sign design using both Chinese and English, and make sure the appropriateness of ratio between graphic and text. Use more of sans-serif font, which has better legibility. (2) Match the color mainly as yellow background with black graphic, blue background with white graphic, white background with black graphic, white background with blue graphic, a strong contrast between background and graphic on brightness and chroma matches the principle of visibility, legibility, and identity. (3) Simplify the signs design may safeguard its visibility. When elder need to handle illness comes from degeneration alone and go to large and complex hospitals frequently, the decay of their mental and physical might have a huge
\end{abstract}

\footnotetext{
* Acknowledgement: The current research is the part of result of research project of Ministry of Science and Technology (Ref. No:104-2410-H-130-049-). Indebted for the subsidy.

FEI Man-chang, Ph.D., Associate Professor, Department of Digital Media Design, Ming-Chuan University.
} 
negative affect. Therefore, the signs design in hospital should understand their properties and design signs that match their requirement, to safeguard their live independency.

Keywords: elderly, hospital, wayfinding, signs

\section{Introduction}

\section{Background}

The life expectancy in Taiwan had raised due to the development of socioeconomic, medical and change in life style, which brings about a higher ratio of older population. The ratio of people aged above 65 in Taiwan was $7 \%$ in 1993, which meets the standard of aging society set by WHO. At meantime, the birthrate reaches its lowest point repeatedly. The data from Ministry of the Interior indicates the number of newborn was 120,099 in first half of 2015, it is a dramatic drop compare to 10 years ago, which number of newborn was 205,854 in 2005 (Ministry of the Interior indicates, 2016). The constitution of population had dramatically changed these years. It turns into an elder and low-birthrate society. Therefore, the ratio of elders living along is increasing yearly. The caring of elders in their illness and living will become an obvious problem for the society in the future. When the elders need to deal the illness and go to hospital along, decays come from degeneration might have affect on their activity in hospital. Therefore, whether the elders can identify the road sign system in hospital clearly, find the right direction, location, and move smoothly in the accessible environment becomes an important issue in the current research.

\section{Article Review}

The current research start from the physical, psychological degeneration of elders, signs design of wayfinding, and principle of signs design for elders to understand the effect of signs design of wayfinding to elders in hospital.

\section{The Psychological Degeneration of Elders}

$\lceil$ Degeneration」 is the decay of physiological, psychological, and social function, which caused by the aging but not of illness. This is a process everyone will go through. The following article will discuss some character of psychological degeneration of elders.

Cognitive change of elders. Cognition is a conscious mental process of gaining knowledge and understanding of world from sense, imagine, identify, learn, memorize, think, reason, judge (Sternberg, 2005). An individual might not able to identify the people or object in the surrounding, reason and judge, abstract thinking, lack of memory, linguistics and numerical ability due to some cognitive deficits caused by damage or pathology in brain. Elders might have some of these deficits in varying degrees caused by the degeneration of brain or limited cognitive ability (Jeng, 2006). The cognitive property of elders is the speed of information process slowed by their physical condition in ageing. This is the result of decay of neural system function and memory capacity (Sternberg, 2005; H. Z. Peng \& J. X. Peng, 2013).

Decay of memory. Memorize is a complex process, start from the stimuli in environment, including vision, hearing, touch. After some filers, we focus on the information we want, and thus these enter the short term memory. The "memorize" and "recall" of an individual includes three important cognitive process: (1) Putting the information in to the memory, called "encoding". (2) Keeping the information, called "storage", the information usually stored in the short term memory, and will enter the long term memory if stimulated or 
practiced repeatedly. (3) The "retrieval" of memory. If elders confront some problem in encoding or storage, there will be obvious memory decay (Wang, 1987).

The speed of information processing. In addition to problem of the joint, another reason of slowness of elders is the degeneration of their peripheral nervous system. Decelerate of delivery in nervous system comes together with aging. The process of stimuli to brain, brain giving order to motor neuron thus drive the muscle, takes longer, but this is just part of the reason causing the slowness of elders. In fact, the time consume of information processing was affected by the task complexity. When the task becomes more complex, there will be bigger difference in age, and slower in speed (Lin, 2008). The most salient property of psychological degeneration of elders is change in cognition, decay of memory, and decelerate of information processing.

\section{The Physical Degeneration of Elders}

The physical degeneration of elders usually indicates decay of efficiency in physical function. Repairing functions ebb by the age, this causes the decay of basal metabolic rate, cardio-pulmonary, kidney, and neural system function, thus result in the aging of organs and some of the mechanisms in body. The phenomenon of aging including the change in skin, vision, hearing, urinary system, skeleton, muscle, joint, cranial nerves system, cardiovascular system, respiratory system, metabolic system, gastrointestinal system, and immune system (H. Z. Peng \& J. X. Peng, 2013). Between all of these decays, vision is most related to the topic of current research.

People's vision decays by the age. It is common to find elders having problem of visual accommodation, and the most serious visual defect is to loose accuracy. These kind of problem can be eased by a high contrast illumination (Stuart-Hamilton, 2008). Elders have worse adaption due to their degeneration of pupil, thus the dark adaptation decelerate by age. Additionally, degeneration of lens affects their ability to identify the color, elders have a yellow shade in their world. Elders can see yellow end (red, orange and yellow) in light spectrum more clear but colors like green, blue or purple would be difficult for them to identify. There is also defect inperception of width and depth due to the smaller range of vengeance, this could cause the lost of visual boundary (Shimonaka, 2007; Yeh \& Chung, 2008; H. Z. Peng \& J. X. Peng, 2013).

\section{The Meaning and Function of Signs Design of Wayfinding}

Signs design plays a vital role in the field of wayfinding. Signs provides a quick access of information to people with different background (Mulakoshi, 2007). Wayfinding usually set for an environment which is large-scale, complex and easy to get lost. In these environment, people would need some assist for finding their destination. Signs can provide simple iconic information for specific location, service or action. The basic mission of signs is to provide identification of airport, station, mall, building, hospital and other facilities in the public space. They usually appear with text instruction or indicator works independently, these can facilitate the communication efficiently. The function of signs is to eliminate the barrier of language and make everyone understood in their live (Mulakoshi, 2007; Gibson, 2009).

\section{The Visual Component of Signs Design of Wayfinding}

The visual component of signs design of wayfinding including color, graphic and text, describes as follow:

Color. Color can provide people identification and guidance on their location. Color choice of design of wayfinding should take contrast and legibility into account. It is necessary to have enough contrast between text or graphic on sign, to make it easier to identified. For example, Americans with Disabilities Act (ADA) suggest there should be $70 \%$ contrast between text and background (Gibson, 2009). Many countries have their standard safety color, which stands for different meaning. For example, JIS in Japan set yellow for "attention", orange for 
"danger, caution", red for "fire, prohibit, stop, danger", cyan for "indicate, warn", green for "safe, refuge, hygiene, care", white for "clear, passage", black for "text, mark", and purple for "radiation". The safety color principle from JIS had became worldwide recognized color figure language (Mulakoshi, 2007).

Pictograms and lettering. The principle of pictograms design including standardization, consistency, simplicity, clear communication, and compatibility. To deliver the visual image from concrete object. The text is an important element of the sign, so the visibility of text would be the first priority. Generally speaking, it is recommended to use san-serif, bold font (Research, Development and Evaluation Commission, Executive Yuan, 2013).

\section{Classification System of Wayfinding}

Japanese Industrial Standards (JIS) separate signs design of wayfinding into eight categories: Public facilities, Transport facilities, Commercial facilities, Tourism, culture, Sport facilities, Safety, Prohibition, Warning and Mandatory (Mulakoshi, 2007). In Taiwan, National Development Council had established "The Wayfinding Handbook" (Research, Development and Evaluation Commission, Executive Yuan, 2013) based on the design handbook from American Institute of Graphic Arts. The wayfinding could be categorized based on their function and information delivered as: Identification, Directional, Orientational, Informational, Regulatory, and Ornamental.

The current research focus on the affect of signs design to elders in hospital, and surveys the National Taiwan University College of Medicine, which is a large scale and complex public space. The research takes the previous three wayfinding category systems and separate the wayfinding in National Taiwan University College of Medicine into five types: Public Facilities, Prohibition, Safety, Warning, and Commercial Facilities.

\section{Principle of Signs Design for Elders}

Elders may confront some cognitive defect, information processing deceleration, visual defect just like the article previously mentioned. As a result, the following properties should be taken into consideration when designing sings for elders (Chen \& Yang, 2008; Gibson, 2009): (1) The proper ratio of graphic and text. (2) The degeneration of elder's lens affects their ability to identify the color, they have a yellow shade in their world. Elders can see yellow end (red, orange and yellow) in light spectrum more clear but colors like green, blue or purple would be difficult for them to identify. So it is important to avoid using colors or matches difficult to identify by elders, like purple, blue and green. (3) Signs should be visually salient, and there should be enough contrast between text and background. Take the visibility, legibility, identity, attention, and memory into account. If typesetting is good, think about the color match, just like suggestion from Americans with Disabilities Act (ADA), to have $70 \%$ contrast between text and background. (4) Avoid using multi-meaning graphic, keep the design simple. (5) Understand the viewing distance of elders on the visual icon.

In summary of elders' physical and psychological degeneration above, most salient psychological degenerations include the change in cognitive function, decay of memory, and deceleration of information processing; physical degeneration includes the decay of vision. It is necessary to take these properties into account when designing wayfing in hospital to meet the elders' demand and safeguard their live independency.

\section{Method}

The research reviewed the degeneration in both physical and psychological of elders and the proper principal of signs design for elders to gain insight of the affect of signs design to elders in hospital. The research 
surveys in Taipei City, which has densest medical center, and mainly focus on National Taiwan University College of Medicine, which has hundred years of history (founded in 1895). The research conducts field survey in both old and new buildings of National Taiwan University College of Medicine in August, 2015. The survey includes five types of signs design: Public Facilities, Safety, Prohibition, Warning, and Commercial facilities.

The signs design of wayfinding in National Taiwan University College of Medicine demonstrated in Figure 1.

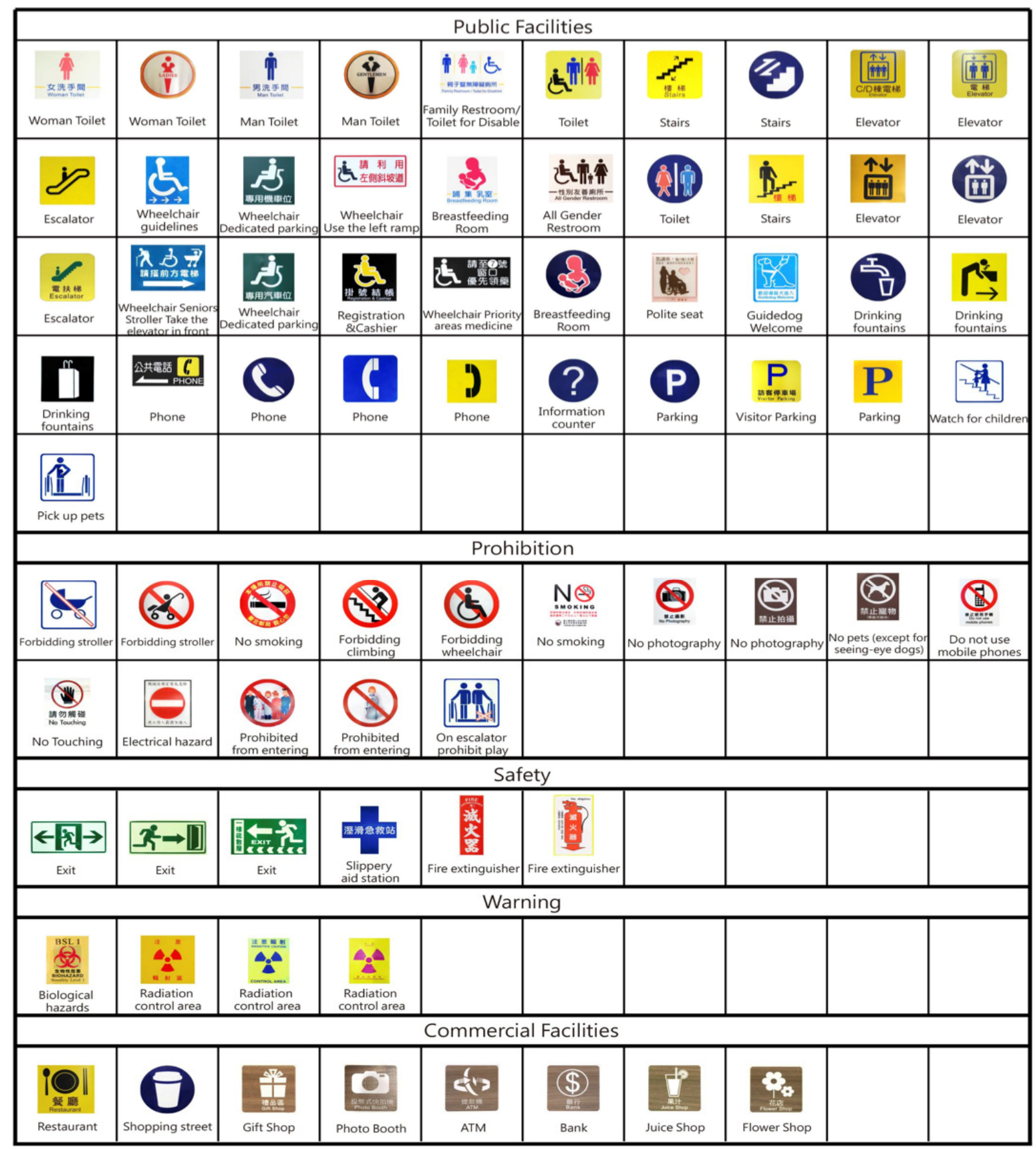

Figure 1. Signs design of wayfinding in National Taiwan University College of Medicine. 
The result of survey indicates the five categories of wayfinding in National Taiwan University College of Medicine including 41 public facilities signs, 15 prohibition signs, 6 safety signs, 4 warning signs, and 8 commercial facilities signs. The visual component of signs design of wayfinding including color, graphic and text, the follow will discuss character of wayfinding in National Taiwan University College from these three dimensions:

- Color: Just as mentioned in previous article, color choice of design of wayfinding should take contrast and legibility into account. It is necessary to have enough contrast between text or graphic on sign, to make it easier to identified. Match the color mainly as yellow background with black graphic, blue background with white graphic, white background with black graphic, white background with blue graphic, a strong contrast between background and graphic on brightness and chroma matches the principle of visibility, legibility, and identity.

- Pictograms and lettering: Using mainly on graphic and text as subsidiary, part of the sign design using both Chinese and English, and make sure the appropriateness of ratio between graphic and text. Use more of sans-serif font, which has better legibility. Simplify the signs design may safeguard its visibility.

\section{Result}

The result indicates the most salient psychological degenerations includes the change in cognitive function, decay of memory, and deceleration of information processing; physical degenerations includes the decay of vision. As a result, the following properties should be taken into consideration when designing sings for elders: (1) The proper ratio of graphic and text. (2) Avoid using colors or matches difficult to identify by elders, like purple, blue, and green. (3) Take the visibility, legibility, identity, attention, and memory into consideration, there should be $70 \%$ differentiation in contrast between text of sign and background. (4) Avoid using multi-meaning graphic, keep the design simple.

The result of survey in National Taiwan University College of Medicine for five categories of wayfinding indicates: (1) Using mainly on graphic and text as subsidiary, part of the sign design using both Chinese and English, and make sure the appropriateness of ratio between graphic and text. Use more of sans-serif font, which has better legibility. (2) Match the color mainly as yellow background with black graphic, blue background with white graphic, white background with black graphic, white background with blue graphic, a strong contrast between background and graphic on brightness and chroma matches the principle of visibility, legibility, and identity. (3) Simplify the signs design may safeguard its visibility.

When elders need to handle illness comes from degeneration alone and go to large and complex hospitals frequently, the decay of their mental and physical might have a huge negative affect. Therefore, the signs design in hospital should take their properties into account and design signs that match their requirement, to safeguard their live independency.

\section{References}

Akase, T. (2013). Signology for public spaces. Tokyo: Kajima Publishing Company.

Chen, J. H., \& Yang, D. M. (2008). Introduce to visual communication design. Taipei: Chuan Hwa Book.

Gibson, D. (2009). The wayfinding handbook: Information design of public places. Princeton, NJ: Princeton Architectural Press.

Li, Y. Z. (2006). Cognitive psychology. Taipei: Wunan Publishing Company.

Ministry of the Interior Department of Statistic. (2016). The Bulletin of Interior Statistics: Statistic of newborn during Jan. to Jul, 2015. Ministry of the Interior Department of Statistic.

Mulakoshi, A. (2007). World wide visual symbols “PICTOGRAM”. Tokyo: Seikai Bunnka Publishing Company.

Peng, H. Z., \& Peng, J. X. (2013). The psychology of aging. Shin Pei: Yang Zhi Culture Publishing Company. 
Research, Development and Evaluation Commission, Executive Yuan. (2013). The Wayfinding Handbook. Taipei: Research, Development and Evaluation Commission, Executive Yuan.

Shimonaka, Y. (2007). The psychology of aging. Tokyo: Baifukann.

Sternberg, R. J. (2005). Cognitive psychology. Taipei: Yeh Book Gallery.

Stuart-Hamilton, I. (2008). The psychology of aging: An introduction. Taipei: Wunan.

Wang, K. S. (1987). Psychology of learning. Taipei: Laureate.

$\mathrm{Wu}, \mathrm{L}$. F. (2013). The new version of gerontological nursing. Taichung: Wagner Publishing.

Yang, L. J. (2007). Aged people life cognition adaptability design. Taipei: Tingmao. 